\title{
Gestão empreendedora em uma empresa familiar de pequeno porte de uma cidade do interior de Minas Gerais
}

DOI: 10.47224/revista master.v6i11.110

\author{
Danilo Faria de Moura \\ Emanuel Soares Ponciano \\ Amanda Borges de Oliveira \\ Anna Gabrielly Castro Ribeiro \\ Ihelle Helena Cavalcante Ferreira Moreno \\ Jaíne Souza dos Santos \\ Victor Hugo Martins Pereira \\ Wagnerson Batista Neves
}

e-mail:danilofmoura@yahoo.com.br

\section{Resumo}

Este artigo tem por objetivo apresentar um estudo acerca da gestão empreendedora em uma empresa familiar de uma cidade do interior de Minas Gerais. A abordagem é fruto da reflexão inicial consequente de uma pesquisa no curso de Administração que visa estudar e analisar a gestão de liderança e o processo de sucessão nessas empresas. As empresas familiares contribuem para o desenvolvimento da região e das comunidades, ocupando uma posição de destaque no âmbito dos negócios. Utilizando de uma metodologia do Arco de Maguerez, observou-se que as principais dificuldades na gestão empresarial desse tipo de organização, referem-se à realização da transferência de poder de uma geração para outra, aos obstáculos para o processo de profissionalização e aos conflitos entre os familiares. A base teórica apoiou-se em pesquisa bibliográfica, com selecionados livros e artigos que convergem com a temática. A partir das problemáticas levantadas desenvolveu-se hipóteses de solução e uma possível aplicação à realidade, que não foi possível realizar, de fato, em virtude da pandemia da Covid-19. Conclui-se que é importante que a empresa não invista apenas nos familiares atuantes na organização, mas também procure criar oportunidades para o restante da equipe que a compõe, ou seja, familiares e não familiares em termos de gerenciamento e sucessão, pois o comportamento organizacional e a sobrevivência estarão fortemente pautados pelas atitudes relacionadas a estes fatores.

Palavras-chave: Empreendedorismo; Administrador Empreendedor; Administração de empresas.

\begin{abstract}
This article aims to present a study about entrepreneurial management during a closed corporation during a city within the interior of Minas Gerais. The approach is that the results of the initial reflection resulting from a search within the Administration course that aims to review and analyze the leadership management and therefore the succession process in these companies. Family businesses contribute to the event of the region and therefore the communities, occupying a prominent position within the business sphere. employing a Arco de Maguerez methodology, it had been observed that the most difficulties within the entrepreneurial management of this sort of organization ask the belief of the transfer of power from one generation to a different, the obstacles to the professionalization process, and therefore the conflicts among relations. The theoretical base was supported by bibliographical research, with selected books and articles that converge with the theme. From the issues raised, we developed hypotheses for solutions and a possible application to reality, which wasn't possible, in fact, thanks to the Covid-19 pandemic. The conclusion is that it's important that the corporate not only invests in relations working within the organization, but also seeks to make opportunities for the remainder of the team that creates it up, that is, relations and non-family members in terms of management and succession, because the organizational behavior and survival are going to be strongly guided by attitudes associated with these factors.
\end{abstract}

Keywords:

Entrepreneurship; Entrepreneurial Administrator; Business Administration. 


\section{INTRODUÇÃO}

Segundo definição de Barreto (1998, apud Coelho, 2011, documento online) "o empreendedorismo é a habilidade de se conceber e estabelecer algo partindo de muito pouco ou quase nada." Timmons (1994, apud Dorabela, 2006, p. 30) ressalta a importância do empreendedorismo atualmente ao citar que "o empreendedorismo é uma revolução silenciosa, que será para o século 21 mais do que a revolução industrial foi para o século 20."

O presente artigo é resultante de atividades orientadas desenvolvidas no Curso Administração em um Centro Universitário de uma cidade do interior de Minas Gerais. Sua elaboração deu-se por meio da Metodologia da Problematização com o Arco de Maguerez e vivenciada tendo como marco norteador a seguinte temática: desenvolvimento de habilidades administrativas em empresas de pequeno porte. A base teórica apoiou-se em uma pesquisa bibliográfica, com selecionados livros e artigos que convergem com a temática.

O objetivo principal trata-se de resolver a problemática de uma empresa do setor alimentício, em que os sócios apresentam formas de pensar e gerir o negócio com divergências, pois ambos, em momentos diferentes, acreditam que, por serem autônomos e donos do negócio, podem estabelecer rotinas de trabalho conforme seus interesses pessoais, gerando discordância e conflitos entre eles, além de impactar diretamente na prestação de serviços.

Maximiano (2012, p. 5) afirma que "noção de autonomia propagada pelo empreendedorismo está relacionada à ausência de necessidade que o empreendedor tem de depender da aprovação de terceiros para a tomada de decisão." O autor destaca como desvantagens de ser empreendedor o sacrifício pessoal, a sobrecarga de responsabilidades e pequena margem de erro, fatores que contribuem para que a autonomia seja utilizada de forma responsável e com compromisso.

Para Maximiano (2012, p.4) "a noção de administração pode ser considerada um dos fatores que favorecem um espírito empreendedor com mais consistência organizacional." Evidencia-se a falta de conhecimento dos sócios da empresa pesquisada referente ao empreendedorismo e administração, e ainda que possuem engajamento e demonstram vontade para que o negócio tenha sucesso.

Dornelas (2008, p. 22) descreve que "empreendedorismo é o envolvimento de pessoas e processos que, em conjunto, levam a transformação de ideias em oportunidades." É possível perceber, correlacionado à visão do autor, que a empresa observada é dotada de pessoas criativas para as oportunidades e se envolvem no processo, porém ainda de maneiras distintas.

Destaca-se a relevância da temática, e do artigo em questão, visto que as possibilidades de soluções para a problemática, descrita posteriormente, são de grande potencial e amplitude para a empresa pesquisada e para os autores que buscam aprimoramento de suas capacidades formativas práticas no curso de Administração.

\section{IDENTIFICAÇÃO DO PROBLEMA}

Por meio da observação da realidade realizada in loco no estabelecimento do ramo alimentício, foi possível identificar algumas lacunas na gestão do negócio que podem comprometer sua rentabilidade e estratégia. Há opiniões divergentes entre os sócios sobre o gerenciamento de escalas de trabalho, fazendo com que não haja regularidade no horário de abertura e fechamento do atendimento ao público e fornecimento de serviços, além de folgas não programadas entre os sócios.

As situações observadas refletem diretamente na qualidade dos serviços prestados, na fidelização dos clientes e no clima entre os sócios, que ocasionalmente entram em conflitos.

Observou-se também, e foi comprovado através do currículo acadêmico dos sócios, a falta e conhecimento aprofundado para questões de administração de empresas, em especial para empreendedorismo de negócios de pequeno porte. É possível constatar que há grande vontade e dedicação para manter a empresa aberta, porém sem o foco necessário para as questões mais estruturais.

Maximiano (2012, p. 4) expõe que "pessoas que desejam empreender estão dispostas a correr riscos ao encaminhar uma iniciativa no mundo dos 
negócios, seja em um produto seja em um serviço." $\mathrm{O}$ autor indica ainda que à medida que as empresas crescem, a necessidade conceitual e estrutural das práticas vai se tornando crucial para a condução e a manutenção do negócio e que empreendedores não necessariamente passaram por formação de administração, mas desenvolveram seus empreendimentos baseando-se em premissas que essa área do conhecimento estuda e busca melhor compreender.

É evidente a falta e conhecimento aprofundado para questões de administração de empresas, em especial empreendedorismo para negócios, na empresa de escolhida para o desenvolvimento dessa pesquisa, sendo essa a problemática abordada por esse artigo. Esses fatores foram detectados e comprovados através de visitas in loco, além de entrevistas direcionadas com os sócios que pontuaram suas dificuldades acerca dessa variável.

A união entre criatividade, empreendedorismo e inovação é destacada por Bessant e Tidd (2019) como fundamental para que as oportunidades de negócios sejam reconhecidas e bem gerenciadas por seus idealizadores. Os sócios da empresa pesquisada apresentam características comuns a muitos que iniciam seus negócios, sejam positivas ou negativas, e diante das análises realizadas foram identificados os possíveis fatores imediatos e os condicionantes maiores, associados ao problema em questão.

\section{Possíveis fatores imediatos:}

- Controle financeiro defasado

- Ausência de estruturação da empresa: definição do modelo de negócios;

- Opiniões divergentes entre os sócios sobre o gerenciamento de escalas de trabalho;

- Conhecimento superficial para questões de administração de empresas.

\section{Possíveis condicionantes maiores:}

- Gaps no fluxo de caixa que podem comprometer o negócio;

- Gestão de atendimento ao cliente ineficiente;
- Falta de regularidade em horário de funcionamento para prestação de serviços;

- Ausência de estratégias de manutenção e expansão do negócio.

As reflexões, considerando os fatores imediatos e os condicionantes maiores, associados ao problema, possibilitam destacar, para o presente artigo, alguns aspectos essenciais ou Pontos-chave:

- Desenvolvimento de habilidades administrativas;

- Alinhamento de escala de trabalho adequada ao horário de funcionamento oficial do estabelecimento;

- Gestão de conflitos e comunicação entre os sócios.

Serão apresentados a seguir o aprofundamento teórico na temática com base nos pontos-chave eleitos.

\section{O EMPREENDEDORISMO EM EMPRESAS FAMILIARES}

Chiavenato (2007, p. 3) ressalta que "o empreendedor é a pessoa que inicia ou opera um negócio para realizar uma ideia ou projeto pessoal assumindo riscos e responsabilidades e inovando continuamente." Compreende-se a importância de assumir riscos e responsabilidades de forma sistematizada para obtenção dos melhores resultados para o negócio.

A ênfase nos estudos sobre empreendedorismo é cada vez maior e esses se aplicam a empresas familiares, que se apresentam como propulsoras das economias da grande maioria dos países, inclusive do Brasil. Apesar das pesquisas sobre tais temas serem numerosas, a teoria avança de forma gradativa e lenta.

Bom Ângelo (2003, p. 25) afirma que "o empreendedorismo é a criação de valor por pessoas e organizações trabalhando juntas para implementar uma ideia por meio da aplicação de criatividade, capacidade de transformar e o desejo de tomar aquilo que comumente se chamaria de risco." Assim, em destaque, as pessoas que se emprenham em abrir seus próprios negócios devem 
ter a capacidade de gerenciamento de situações que envolvem o atendimento ao cliente e as variáveis administrativas.

Ao realizar uma reflexão sobre a pesquisa em empreendedorismo nas empresas familiares, observa-se que poucos são os padrões conceituais estabelecidos, o que gera uma diversidade de estudos, sem uma convergência teórica e metodológica.

O empreendedorismo tem se tornado ao longo dos anos uma importante área para o incentivo à criação de novos negócios, sendo que vários países têm realizado ações para incluir o ensino de empreendedorismo nos currículos de ensino básico e superior, como forma de estimular a educação empreendedora. (VIEIRA, et al., 2013, p. 2)

\section{HABILIDADES ADMINISTRATIVAS PARA SUCESSO NOS NEGÓCIOS}

Os autores Guilhon e Rocha (2000, p. 46) colocam que, "para atender às demandas competitivas do novo contexto organizacional, a liberdade de ação em todos os níveis da empresa e o modo participativo, deve ser a regra de conduta e orientação gerencial no processo de gestão permanente da mudança."

Como afirmam Pryor e Shays (1993, apud Lizote e Verdinelli, 2014, p. 5) "as empresas proativas caminhavam nessa direção, pois a descentralização na tomada de decisão estava sendo incorporada ao planejamento estratégico, com vistas à diminuição do custo operacional e a elevação da qualidade dos serviços ou produtos que ofertam, com a participação direta dos funcionários."

Dessa forma, é destaca-se que as habilidades para o negócio podem ser desenvolvidas com 0 aprendizado no cotidiano, pois comportamentos empreendedores começam a melhor os processos e criar oportunidades de negócio, isso é denominado de empreendedor intracorporativo ou intraempreendedores.

Chiavenato (2007, p. 161) destaca que intraempreendedores "são pessoas que proporcionam a excelência, a qualidade, a produtividade e competitividade da empresa." Assi, intraempreender se refere à intenção de um indivíduo de apresentar suas próprias ideias e, em seguida, colocá-las em prática com a ajuda de recursos de assistência e gestão. Esses indivíduos assumem riscos, procuram transformar uma ideia em um negócio lucrativo dentro do ambiente organizacional em que estão inseridos.

\section{GESTÃO DE ESCALA DE TRABALHO}

\begin{abstract}
"As escalas de Trabalho têm sido estudadas ao longo do tempo, à medida que surgem organizações com demandas diferentes de trabalho como call centers, companhias aéreas, supermercados, hospitais, serviços postais, varejo em geral, entre outros. Com essa carga horária máxima definida, empresas principalmente as de produção ininterrupta começaram a implementar escalas que variam em turnos, horários e dias da semana, para não prejudicar a produção. (ALVES, 2019, documento online)
\end{abstract}

A gestão de escalas de trabalho se faz extremamente importante, considerando que a equipe do restaurante tem sua jornada de trabalho das $16 \mathrm{~h}$ à meia-noite, e que cada 5 dias trabalhados o funcionário tem o direito de um dia de folga, com direito a um domingo de folga por mês.

Se o funcionário trabalhar nos finais de semana, a cada, no máximo, 7 semanas, ele terá direito a um domingo de folga, o que é o mesmo escala de trabalho geralmente usada por profissionais de saúde, montadoras de veículos, bombeiros, entre outros.

Compreende-se, pelo exposto, que se faz possível afirmar que os esforços necessários não são grandes para se estabelecer uma escala de trabalho, sabendo ainda que a mais gestão de tempo possibilita identificar quais atividades não agregam valor ao resultado do negócio e eliminá-las sem negatividade. Aplicando a análise de tarefas e a avaliação de alternativas é possível elaborar métodos eficientes de trabalho que melhor atendam os clientes e não sobrecarregue a equipe.

\section{COMUNICAÇÃO E CONFLITOS ENTRE SÓCIOS}

Empresas familiares necessitam de organização, ajuda e união de todos os colaboradores, parentes 
ou não, para que o empreendimento seja promissor, havendo um investimento lucrativo/prazeroso para os envolvidos, é a chamada inter-relação: família versus empresa. Em geral, é relevante que enfatizem mais a gestão da organização do que os laços familiares, seja como detentora do capital e/ou à frente da sua gestão.

De acordo com artigo vinculado pela Revista Brasileira de Administração (2017, documento online) "as empresas familiares representam $80 \%$ das 19 milhões de companhias que existem no país, segundo a Pesquisa de Empresas Familiares no Brasil, divulgada no final de 2016 pela PwC".

Entretanto, Davel e Colbari (2003, p. 48) alertam que "apesar dos indicadores favoráveis, uma visão negativa e um estado de miopia envolvem as percepções relativas ao funcionamento das organizações familiares."

Um dos grandes desafios do empreendedor é a opção por uma definição de empresa familiar, uma vez que diferentes conceitos como ponto de partida e ponto de vista de como gerir podem vir a se tornar conflitos entre os sócios.

\section{HIPÓTESES DE SOLUÇÃO DO PROBLEMA}

Mediante análise das situações citadas, decidiu-se que a implantação de uma planilha de controle de estoques e finanças será de grande valia, pois na empresa se faz necessário:

- Adequação e ajuste da escala de trabalho dos funcionários e sócios;

- Definição de papéis e responsabilidades dos funcionários;

- Sistematização para tratativa de conflitos no ambiente de trabalho;

- Rotina de reuniões e alinhamentos com a equipe.

Ao analisar essas possibilidades, identificou-se a possibilidades de aplicação de todas elas para a aplicação à realidade.

\section{APLICAÇÃO À REALIDADE}

Frente a viabilidade considerando os fatores de custo, complexidade e aplicabilidade das hipóteses levantadas, ações foram realizadas e processos implantados na empresa escolhida para o estudo.

Para o desenvolvimento de habilidades administrativas foram propostas e implementadas planilhas de controle de estoques dos alimentos, bebidas, ingredientes, assim como para o controle financeiro. Cada setor ficou com a incumbência diária de entregar ao fim da jornada de trabalho uma lista com o que necessitará para o outro seguinte, minimizando a incidência de falhas e desfalque na preparação de algum produto.

Para melhor atendimento ao cliente e implantação de uma cultura de fidelização de oferta dos produtos, o horário de funcionamento do estabelecimento precisa ser fixo, com clareza sobre dias abertura e folgas, considerando as particularidades de cada atividade a ser desempenhada. Foi implantada uma rotina em que os funcionários da equipe de cozinha são os primeiros a iniciar a jornada de trabalho para que esteja tudo pronto ao iniciar o atendimento aos clientes com a venda dos produtos.

Com essa organização dos horários esclareceu-se a função de colaborador e estabeleceu-se que nos momentos de ociosidade de suas atividades devem auxiliar os demais funcionários para evitar sobrecargas de setores específicos:

- A cozinha do estabelecimento é liderada por uma cozinheira e conta com um auxiliar que segue suas instruções, diminuindo a incidência de atrasos e trocas de pedidos;

- O caixa conta com um colaborador responsável pela movimentação financeira da noite, envolvendo o fluxo de caixa, além de fazer o controle dos pedidos de delivery, catalogando seus endereços, formas de pagamento $e$ ordem das entregas para o entregador;

- $O$ atendimento no salão é realizado por um funcionário que além de anotar pedidos, realiza a higienização das mesas após desocupadas pelos clientes;

- Na churrasqueira há um responsável por preparar a carne, principal elemento do cardápio, para que sejam servidas em ótima qualidade e tempo aceitável. 
Entende-se que a gestão de conflitos e comunicação entre os sócios é a peça-chave para o funcionamento do estabelecimento, partindo da premissa que devem ser exemplos de comportamentos para que seus funcionários os sigam e mantenham um padrão. Assim, definiu-se entre os sócios que, havendo algum problema durante o horário de atendimento ao público, não deverão iniciar conflitos ou debates sobre a situação. Para essa tratativa será reunida a equipe envolvida após a jornada de trabalho apurando o ocorrido e determinando o que poderá ser feito para que não haja reincidências, ouvindo todas as partes envolvidas, uma de cada vez.

Para o alinhamento constante da equipe de trabalho os sócios se comprometeram a ter uma rotina com seus funcionários uma vez na semana para debaterem os principais acontecimentos daquele período, além de pontuarem o que não está em conformidade para melhor convivência e juntos buscarem alternativas para benefício de todos.

Os sócios compreenderam que devem trabalhar com o máximo empenho e dedicação, para assim obterem o melhor desempenho da equipe, pois são os mais interessados no sucesso da empresa.

\section{CONSIDERAÇÕES FINAIS}

De acordo com o que foi apresentado neste artigo, pode-se considerar que as principais dificuldades enfrentadas pelos empreendedores de pequeno porte são: falta de um planejamento, incompatibilidade entre a visão estratégica dos sucessores e a dos fundadores, centralização do poder pelo fundador, porém não se pode afirmar que, seguindo todas as sugestões propostas, um gestor fará uma boa sucessão. É preciso atentar-se para vários fatores que interferem, tais como: a identificação do sucessor com a área, o contexto organizacional, o momento econômico, dentre outros.

As empresas familiares enfrentam desafios que podem conduzir ao fracasso do negócio e rupturas familiares, principalmente quando o ambiente é de sucessão da administração. O que tem sido mais comum observar nessas empresas é que muitas delas acabam desaparecendo no momento da troca de comando, principalmente pela ausência de um planejamento adequado de quem assumirá a liderança e de que forma isso irá ocorrer.

A ausência de planejamento pode levar a um processo de sucessão forçado por alguma situação inesperada, como, por exemplo, saúde debilitada do fundador ou dificuldade financeira da empresa, com necessidade de reestruturação, ou ainda, as duas situações simultaneamente.

Os conflitos no ambiente de trabalho acontecem de forma natural e surgem em diversos momentos com o ingresso das novas gerações no meio corporativo. São diversos os pontos de vista e os interesses envolvidos e o processo enfrenta questões delicadas, como na hora de eleger os novos líderes, restringir participações, delegar, dividir poderes e profissionalizar a gestão. Há preocupação com a possibilidade de que conflitos familiares, indiferença ou falta de profissionalismo possam prejudicar a capacidade de prosperidade da empresa, destruindo o suporte financeiro para a família e corroendo o legado e a instituição que se esforçaram tanto para construir. É perfeitamente possível que a empresa familiar venha a ser um empreendimento de sucesso, desde que exista um equilíbrio entre a realização profissional e a dependência financeira.

Assim, é importante que a empresa não invista apenas nos familiares atuantes na organização, mas também procure criar oportunidades para outros membros da equipe, ou seja, familiares e não familiares, em termos de gerenciamento e sucessão, pois o comportamento organizacional e a sobrevivência estarão fortemente pautados pelas atitudes relacionadas a estes fatores.

\section{REFERÊNCIAS}

ALVES, D. R. Escalas de Trabalho: Tudo que você precisa saber. Escala de trabalho. Disponível em: https://escalasdetrabalho.com.br/o-que-saoescalas-de-trabalho/. Acesso em 20 jun. 2020.

As empresas familiares guardam em sua essência os valores de seus membros. Revista RBA.

Disponível em: https://revistarba.org.br/tudo-emfamilia/. Acesso em 19 jun. 2020.

\section{BOM ÂNGELO, Eduardo. Empreendedor}

corporativo: a nova postura de quem faz a diferença. Ed. Rio de Janeiro: Editora Elsevier, 2003. 
CHIAVENATO, Idalberto. Empreendedorismo: dando asas ao espírito empreendedor. 2. Ed. São Paulo: Saraiva, 2007.

COELHO, Tayane Cristina. Empreendedorismo no mercado da moda: um estudo exploratório sobre os desafios e oportunidades em empreender no mercado varejista de moda feminina. 2011.

DAVEL, Eduardo; COLBARI, Antônia. Organizações familiares: por uma introdução a sua tradição, contemporaneidade e multidisciplinaridade. Revista Organizações e Sociedade. v. 7, n. 18, p. 4564, maio/ago. 2000.

DOLABELA, Fernando. O segredo de Luísa: uma ideia, uma paixão e um plano de negócios: como nasce o empreendedor e se cria uma empresa. 14. ed. São Paulo: Cultura, 2006.

DORNELAS, José Carlos Assis. Empreendedorismo corporativo: como ser empreendedor, inovar e se diferenciar na sua empresa. 2. ed. Rio de Janeiro: Elsevier, 2008.

GUILHON, P. de T.; ROCHA, R. A. da. Intrapreneur: multiplicador de novos negócios. Revista Alcance, ano VI, n. 1, p. 45-51, 2000.

LIZOTE, Suzete Antonieta; VERDINELLI, Miguel Angel. Competências empreendedoras: um estudo com funcionários administrativos de uma empresa do ramo alimentício. Revista Pensamento Contemporâneo em Administração, v. 8, n. 1, p. 164-182, 2014.

MAXIMIANO, A. C. A. Empreendedorismo. São Paulo: Pearson Prentice Hall, 2012.

TIDD, Joe; BESSANT, John R. Gerenciando a inovação: integrando a mudança tecnológica, de mercado e organizacional. John Wiley \& Sons, 2019.

VIEIRA, Saulo Fabiano et al. Ensino de empreendedorismo em Cursos de Administração: um levantamento da realidade brasileira. Revista de Administração FACES Journal, 2013. 